\title{
Shaanxi Somewhere Mountain Geological Hazard Assessment for Construction Projects
}

\author{
Xiao Qiang Wu \\ (yanan university construction engineering school, shaanxi yanan,china, 716000). \\ Email:nwwolf197724@163.com.
}

Keywords: Mountain planning survey; Geological hazard assessment; Disaster prevention ; Control measures ; Design

\begin{abstract}
. the site engineering geological conditions of mountainous area construction play a crucial role of project planning and site selection, construction projects in the engineering survey in the mountains, to pay attention to the engineering geological survey and evaluation of geological disasters. Somewhere in northern shaanxi mountainous area construction, geological hazards assessment, district planning and decision making for similar areas to provide prevention and control of geological disasters related technical indicators, reasonable prevention and control measures are put forward.
\end{abstract}

\section{The introduction}

Mountain geological environment and residential planning and construction is a complex process of multi-factor, multi-level, in planning how to choose to use, to adapt to the transformation of geological environmental conditions, prevention and control of environmental geological problem that may occur, reducing the occurrence of geological hazards, there is no doubt that it is very important and necessary. In engineering construction planning and site selection, building design and construction of the whole process, is available to engineering geological prospecting work to make due contributions.

Somewhere in northern shaanxi, our team in engineering geological investigation of a residential district, to the study on geologic hazard problems, analyses the characteristics of the site topography, consider the various factors of the engineering geological environment needs based on geological environment data, find out the geological disaster type, emphatically for the planning and design stage of prevention and control of geological disasters relevant technical indexes, reasonable prevention and control measures are put forward[1 4].

\section{Site location and the status quo}

Somewhere in northern shaanxi of the proposed construction project, the project company, the mountain is in the west, south adjacent to a cigarette factories, the provincial highway to the east.

Project planning. Shaanxi somewhere near village construction project is mainly composed of seven commerce-residence building, building and auxiliary, commercial housing construction area of $114000 \mathrm{~m} 2$. Among them: 1 \#, 2 \# floor level 31; 3 \#, 4 \#, 5 \#, 6 \# building 32 layer; 7 \# building 28 layer; Projects with a total investment of about 300 million yuan, capital source for oneself. The project covers an area of $26472.8 \mathrm{~m} 2$ (39.71 acres), controlled by 44 a turning point, 


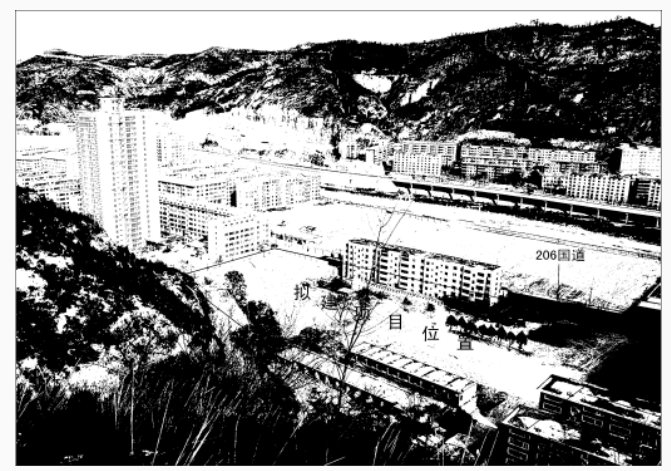

Figure. 1 site environment will figure

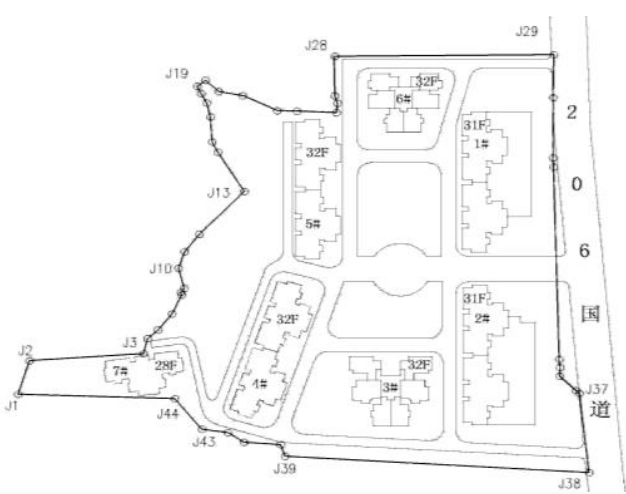

Figure. 2 general layout

Topography. Certain radioactive-polluted area is located in the northern shaanxi loess plateau central, belongs to the typical mixed inheritance and inheritance, erosion gully region of loess Liang Mao. In underlying Jurassic middle bedrock ancient terrain undulating, under the influence of the new tectonic movement, as a result of river erosion cutting for a long time, formed the current Liang Mao ups and downs, deep valley terrain. Proposed site is located in yan level terrace, survey area landscape can be divided by its causes Liang Mao loess area and river region[5 8].

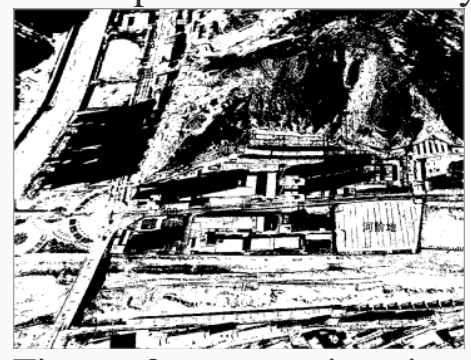

Figure. 3 construction sites geomorphological map

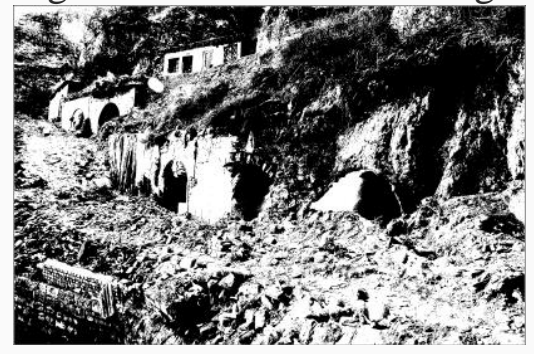

Figure. 4 dismantle cave after partial collapse hazard

The formation lithology. According to the existing data and the survey, which is the main development zone Cenozoic strata, including the Jurassic middle yanan group and quaternary strata. Quaternary system throughout the district, the west side of the Jurassic strata in the proposed site have exposed slope foot, about 5-10 m high, covered by quaternary strata. According to field investigation and the reference of near field of geotechnical engineering investigation report, formation by sophisticated new points mentioned below:

(1) the Jurassic yanan group (J2y) : middle distributed in the proposed site below about 10 to 15 $\mathrm{m}$ below, in the west side of the field have exposed loess slope foot, as a set of gray, gray, thick layer of coarse quartz sandstone, cross-bedding development. Upper is thin layer sandstone and shale interbed, bottom glutenite and irregular conglomerate, top-down gravel size bigger. This layer has a small line lenticular sandstone and mudstone and coal, and contains iron TB and plant fossils, surface weathering strong, light brown, is porous, tend to form honeycomb structure. With the next layer in contact. (2) in the pleistocene series (Q2eol) : loess in loess Liang Mao area, along the slope Liang Mao exposed, the upper is covered by the new loess and diluvial layer, more is to constitute the main part of the loess Liang Mao, $20 \sim 30 \mathrm{~m}$ thick, lithology of tan, brown pigments clay, clay interlayer palm red paleosol, common TB that contain calcium and calcium omentum, local TB content is higher. Structure is compact, quality of a material is solid, vertical joints growth, bedding, working hard, dark. 
Geological structure. Certain radioactive-polluted area is located in the ordos syncline eastern shanbei area on the concave, gentle stratigraphic, structural feature and simple, less without large drape and fracture, in general is an axial plane to NNE, NW, dip Angle in $1 \sim 4$ DHS monoclinal structure, tectonic joints and the development. Since since the quaternary system in a steady rise in the state, gully development[9 10].

Summary. (1) certain radioactive-polluted area is located in the northwest inland, semi-humid and semi-arid continental monsoon climate, annual average temperature: $10.3^{\circ} \mathrm{C}$, the average annual rainfall of $562.1 \mathrm{~mm}$; (2) evaluation area for YanHeShui system, proposed site about $150 \mathrm{~m}$ from yan, river on both sides have a levee, the risk of geological disaster caused by flood, (3) of the proposed project area is located in yan level terrace, flat, the order of about $200 \mathrm{~m}$ width; Layer (4) certain radioactive-polluted area out of the open country to Jurassic and quaternary, simple geological structure, basic design earthquake acceleration of $0.05 \mathrm{~g}$, reflect the characteristics of the spectrum period $0.35 \mathrm{~s}$; (6) survey of groundwater in the area can be divided into loose rocks and loess pore water, bedrock fissure water, pore water depth of about $12 \mathrm{~m}$, water stability, fissure water development; (7) of the proposed site strong human engineering activities, mainly for industrial and civil buildings are removed, dismantle TuYaoDong easily lead to geological disasters, need dismantled and governance.

\section{Belongs to the important construction project of the proposed construction project.}

Simple - medium field geological environment conditions, the geological hazard of construction engineering estimate will combine characteristics and site engineering geological environmental conditions, in view of the engineering construction may suffer from worsening, and cause the risk of geological disasters, adopt the method of qualitative analysis to forecast evaluation. According to field investigation and analysis, the collapse of hidden dangers, B1, B2, the status quo is in stable state, but in the project construction and after the operation, meet spring rain and freezing and thawing, there are local in danger of collapse, the need for project management. So 7 \# building engineering construction and operation of suffer the risk of geological disasters: medium. 7 \# building is located in the gully, the natural terrain is " $\mathrm{V}$ " glyph, engineering construction site have to be flat, dig soil cutting slope in slope foot, influence the stability of the slope. Thus in the engineering construction, increase the risk of geological disasters: great. Around 7 \# building development, B1, B2, hidden trouble, the collapse in the construction of the surrounding area for leveling, cutting slope, cut the foot, a small but collapsed, easy cause, B1, B2, but building foundation bearing layer on the bedrock, less disturbance on the loess slope in the construction, thus caused in the construction of engineering geological disaster risk: medium. In conclusion that suffered during construction and operation of the proposed construction project, and all kinds of risk of geological disasters are: \# 1 - \# 6 floor is small; 7 \# building.

\section{The comprehensive assessment of geologic disaster danger}

construction site suitability evaluation: according to the result of the comprehensive assessment of geologic disaster danger, danger area, suitable for construction; Dangerous regions, unstable slope, the status quo conditions as poor construction site suitability, take the necessary basic right after the geological disaster prevention and control measures of construction, the prevention and treatment of difficult, prevention and treatment of the high cost.

\section{Advice}

(1) 7 \# protection to qualification units need to be designed, completed rear slope governance for (2) of the building construction all not complete demolition TuYaoDong, need to fill in wall and surface weathering process, prevent the rain from the loess fracture into abandoned inside the cave, formed a new disaster; (3) within 7 \# building located in the gully, should be designed according to the slope catchment area water and drainage . 


\section{References:}

[1] H.M. Su, Static Pressure Precast Pile Influence on Surrounding Buildings and Countermeasures [J]. Architectural technology development, 2000, 27 (6) : 8-9. (In Chinese)

[2] H,R, Zhou, Soil Mechanics and Foundation Engineering [M]. Wuhan: Wuhan university of technology press, 1988(In Chinese)

[3] Z.X. Li, Method and Its Application in Static Load Pile Test [J]. Architectural technology, 2000, 31 (3) : 157-159. (In Chinese)

[4] X.N. Gong. Soil Nailing and Composite Soil Nailing Support Several Problems [J]. Journal of civil engineering, 2003, 4 (10) : 80-83. (In Chinese)

[5]GB50021-2001, the Geotechnical Engineering Specification [S]. Beijing: China building industry press, 2009. (In Chinese)

[6] GB 50330-50330, the Building Slope Engineering Technical Specifications [S].

[7]. The Finite Element Simulation and Stability Analysis of Slope Excavation [J]. Journal of rock mechanics and engineering, 2002, 21 (6) : 843-847.

[8] D.G. Zhang. Theory of Urban Positioning - sociological Theory Under the View of Sustainable Development Strategy [M]. Nanjing: southeast university press, 2008.

[9] DZ/T 0219-2006, the Landslide Prevention and Control of Engineering Design and Construction Technical Specification [S].

[10] Claire markus cooper, etc. Humanity places - urban open space design guide [M]. Sasaki, et al. Beijing: China building industry press, 2001. 